\title{
Participação política no Colegiado Setorial de Culturas Populares, do Ministério da Cultura (MinC): Uma análise a partir dos canais participativos
}

\author{
Giordanna Santos, Universidade Federal da Bahia (UFBA), Brasil
}

\begin{abstract}
Resumo: Os estudos sobre participação e os espaços participativos estão cada vez mais recorrentes nas diversas áreas das políticas públicas, no entanto, nas culturas populares e tradicionais tal debate ainda está incipiente; o que justifica a importância dos estudos desenvolvidos nesse segmento. Dessa maneira, este artigo visa contribuir para a ampliação das investigações e das discussões teóricas no âmbito do campo cultural brasileiro. Assim, são apresentados os resultados da pesquisa de doutorado sobre a participação política no Colegiado Setorial de Culturas Populares, ente vinculado ao Conselho Nacional de Política Cultural (CNPC), que compõem o Ministério da Cultura, no Brasil. Neste artigo são feitos apontamentos obtidos a partir da análise da participação e representação da sociedade civil nesse órgão, tendo como base as reuniões e as atas desses encontros, as normas legais que regem o Colegiado, questionário estruturado para verificar a abrangência da instância e a representatividade dos membros da sociedade civil, bem como entrevistas semiestruturadas com os conselheiros; sendo que o período de realização da investigação foi de março de 2011 a dezembro de 2014. Dentre os resultados obtidos, verificou-se que a participação, apesar de seu potencial, ainda apresenta limitações e fragilidades para que se efetive em sua completude. Um dos obstáculos para maior êxito da instância é a questão da representatividade dos atores da sociedade civil. Além disso, conclui-se que o órgão ainda não possui o diálogo necessário com o segmento cultural, pois a maioria dos entrevistados do setor alega não ter conhecimentos sobre o Colegiado e suas ações.
\end{abstract}

Palavras chave: culturas populares, politicas culturais, participação e representação política, conselhos de politicas

\begin{abstract}
Studies on participation and participatory spaces are increasingly recurrent in the various areas of public policy, however, the popular and traditional cultures such debate is still in beginning; which explains the importance of studies on this area. Thus, this article aims to contribute to the expansion of research and theoretical discussions in the Brazilian cultural field. Therefore, we present the doctoral research results on political participation in the "Colegiado Setorial de Culturas Populares", being linked to the "Conselho Nacional de Politica Cultural" (CNPC), which comprise the Ministry of Culture in Brazil. Appointments are made obtained from the analysis of the participation and representation of civil society in that institute, based on the meetings and the minutes of these meetings, the legal rules governing, structured questionnaire to verify the scope of the proceedings and the representativeness of members civil society, as well as semi-structured interviews with counsellors; being that the research realization period was from March 2011 to December 2014. Among the results, it was found that participation, in spite of its potential, still has limitations and weaknesses to be made effective in its entirety. One obstacle to greater success instance is the issue of representativeness of civil society actors. In addition, it is concluded that the agency does not have the necessary dialogue with the cultural sector, as most the sector interviewees to have no knowledge of the Board and their actions.
\end{abstract}

Keywords: Popular Cultures, Cultural Policies, Political Participation and Representation, Political Council

\section{Apresentação}

$\mathrm{A}$ partir de 2003, vivencia-se no Brasil uma mudança na gestão pública, quando Luiz Inácio da Silva, do Partido dos Trabalhadores (PT), assumiu a presidência da República. Após 13 anos de governo neoliberal ${ }^{1}$, o país passa a ter uma administração voltada para a ver-

\footnotetext{
${ }^{1}$ Na década de 1990, os presidentes brasileiros foram Fernando Collor de Mello (1990-1992), Itamar Franco (1992-1995) e dois mandatos de Fernando Henrique Cardoso (1995-2003).
}

Revista Internacional de Ciencias Humanas

Volumen 5, Número 1, <http://lascienciashumanas.com>, ISSN 2530-4526

(C) Global Knowledge Academics. Giordanna Santos.

Todos los derechos reservados. Permisos: soporte@gkacademics.com

Republicado de Revista Internacional de Estudios Políticos, Cívicos y Comunales 5(1), 2016 (pp. 23-36) 
tente de governo democrático popular. Na cultura, as diretrizes se baseiam no documento "A Imaginação a serviço do Brasil" (PT, 2002). Tal projeto de campanha traz como princípios norteadores a "gestão democrática", "cultura como política de estado", "cultura como direito social básico", dentre outros. Entre as políticas propostas está a criação de um "Sistema Nacional de Política Cultural", que durante sua implantação, na gestão Lula, será denominado por Sistema Nacional de Cultura (SNC). Desde o início, ainda no projeto de campanha, a concepção desse sistema esteve (e ainda continua) ancorada no federalismo cooperativo, com base nos princípios constitucionais, principalmente o de soberania popular. Logo, um dos elementos essenciais para a efetividade desse modelo é a participação social. Dessa maneira, o SNC propõe instâncias participativas, seja de escuta social esporádica, como conferências; ou permanentes, que é o caso dos conselhos de políticas. Para subsidiá-los, podem contar com comissões, comitês, grupos de trabalho e colegiados setoriais. Estes espaços são constituídos por atores da sociedade civil e poder público, que atuam de modo consultivo, deliberativo, normativo, executivo ou fiscalizatório, a depender do que rege a norma.

É nesse contexto que se insere o objeto deste artigo, o Colegiado Setorial de Culturas Populares, que também fez parte da pesquisa de doutorado "Participação Política no Colegiado Setorial de Culturas Populares, do Ministério da Cultura (MinC): uma análise a partir dos canais participativos". O Colegiado de Culturas Populares é um ente da estrutura do Conselho Nacional de Política Cultural (CNPC); este último é dividido por setoriais de cada área temática da cultura. A composição de ambos é paritária e com assentos destinados a sociedade civil - estes são representantes eleitos por seus pares em espaços participativos - e poder público - escolhidos pelo Presidente da República.

O Colegiado iniciou suas atividades em 2010, durante a Pré-Conferência de Culturas Populares, evento realizado pelo Ministério da Cultura para discussão de políticas culturais e no qual se elegeram representantes da sociedade civil para a formação do primeiro mandato do órgão. Dessa maneira, no estudo iniciado em 2011 e concluído em 2014, teve como intuito analisar a participação e a representação no referido Colegiado, durante dois mandatos, sendo estes 20102011 e 2012-2014.

Trabalhou-se com os seguintes problemas: Como se dá a participação política no Colegiado de Culturas Populares? Há efetividade no modelo adotado? O setor das culturas populares participa, acompanha e interage com esse órgão colegiado? Sendo essas perguntas verificadas por meio da análise dos canais de participação e comunicação ${ }^{2}$. No que se refere aos primeiros, foram utilizados dados obtidos a partir das observações in loco, ou seja, durante a participação nas reuniões nos anos de 2010 até 2012, período no qual a pesquisadora integrou o Colegiado como representante da sociedade civil. Além disso, foram utilizadas as atas dessas reuniões e também feita uma análise normativa das regras que regem a instância, bem como são usados dados coletados nas entrevistas com os conselheiros e em um questionário estruturado aplicado com atores do setor, buscando-se verificar sua abrangência e representatividade.

No que se refere as normas legais, utilizaram-se o Decreto que institui o Conselho Nacional de Política Cultural (Decreto $n^{\circ} 5520$ de 24 de agosto de 2005, atualizado pelo Decreto $n^{\circ} .6 .973$, de 2009), o regimento interno do Conselho (Portaria $\mathrm{n}^{\circ} 28$ de 19 de março de 2010), a portaria de nomeação do Colegiado, Regimento Interno do Colegiado. Também foram usados os resultados das Pré-Conferência Setorial de Culturas Populares (2010), do Fórum Setorial de Culturas Populares (2012), da II Conferência Nacional de Cultura, eventos realizados no período pesquisado e nos quais aconteceram as eleições para seleção dos membros do primeiro e segundo mandato do órgão. A partir dos recortes e com base nesses instrumentos, têm-se resultados da abrangência do órgão, da efetividade da participação e da representação, esta última mensurada pela representa-

\footnotetext{
2 Apesar de não integrar o escopo deste artigo, salienta-se que foram usadas como fontes secundárias da investigação de doutorado canais de comunicação, dentre eles os sites do Ministério da Cultura (MinC), blogs do Conselho Nacional de Política Cultura (CNPC), blog do Colegiado Setorial de Culturas Populares; Blog da II Conferência Nacional de Cultura (IICNC).
} 
tividade dos conselheiros. Para este artigo, trazem-se os principais resultados, sobretudo, no que diz respeito à abrangência e representatividade.

\section{Democracia, participação e representação}

A democracia tem sua origem na Grécia Antiga e pode ser traduzida do grego demokratia, que é governo (kratia) do povo (demo). Do seu início, até a contemporaneidade esse conceito passou por várias transformações, inclusive havendo modelos que se opõe e/ou se complementam. Há três principais vertentes que abordam a participação: democracia representativa; democracia participativa e democracia deliberativa. Destas linhas, elegeu-se a democrática participativa para o desenvolvimento das análises em questão.

Nesse sentido, contrapondo-se a linha liberal representativa, a democracia participativa é defendida por teóricos como Pateman (1992), com base em Rousseau, John Stuart Mill, Hannah Arendt, G. D. H. Cole; e Macpherson. Essa vertente é difundida, principalmente, a partir das décadas de 1960 e 1970. De Rousseau veio a inspiração para a compreensão de participação enquanto meio para aperfeiçoamento democrático e de Stuart Mill também foi absorvido o caráter educativo da participação, além da ideia de associativismo. (Pereira, 2007). Os teóricos desse modelo acreditam na relevância da participação para além das eleições e que ela proporciona uma cultura participativa, ou seja, quanto mais os cidadãos veem que suas opiniões são levadas em conta no processo decisório, mais eles irão participar politicamente.

Essas concepções de democracia participativa, como propôs Pereira (2007), estão situadas em uma visão de países desenvolvidos e no contexto da América do Norte. Por isso, deve-se pensar nas especificidades dos países do Sul (América do Sul), que possuem histórico democrático diferenciado e marcado por governos autoritários. Esse modelo de participação do Sul acrescenta dois importantes elementos dessa vertente: 1) a relevância de analisar também as ações diretas dos cidadãos, tais quais paralisações cívicas, passeatas, ocupações, caminhadas; e por fim a existência de um conjunto de reivindicações mais amplos, geralmente vinculado a temas culturais, identitários e reconhecimento social e político; e 2) o papel dos movimentos societários na institucionalização da diversidade cultural. (Pereira, 2007, p.433). Dessa forma, no modelo do Sul, a participação é vista como essencial para "incluir" aqueles atores sociais que foram deixados à margem ou excluídos do processo democrático nos modelos tradicionais, sobretudo, são as chamadas "minorias" identitárias que historicamente foram subjugadas pelos colonialismos e autoritarismo (Pereira, 2007).

\section{Participação nos governos Lula e Dilma}

Apesar de haver, na Constituição Cidadã de 1988, previsão legal de instrumentos de democracia semidireta como plebiscito, referendo e iniciativa popular, apenas a partir de 2003, que há uma ênfase maior em desenvolver ações com intuito de efetivar os preceitos constitucionais da soberania popular e dos instrumentos participativos na área cultural.

Ademais das formas previstas na Constituição, dentre as maneiras de se exercer a participação também estão as conferências e os conselhos nas mais diferentes áreas. Durante o governo Lula foram realizadas 73 conferências nacionais, dentre elas 21 ocorreram uma única vez, nove contaram com duas edições, cinco com três edições e outros cinco com quatro edições entre 2003 a 2010. (Pólis/Inesc, 2011, p.42). Na cultura, foram realizadas duas conferências nacionais, além de vários encontros, seminários e oficinas. São reconhecidos os avanços promovidos pelo expresidente Lula e também que a ideia de democracia participativa no modelo do Sul pode ser associada ao projeto político desse governo.

Com relação, os conselhos de políticas, até 2011 identificam-se 34 conselhos, assim como nesse período a Secretaria-Geral da Presidência da República promoveu três encontros com representantes de 26 conselhos e de duas comissões nacionais. Além das conferências e conselhos 
nacionais, Lambertucci cita outras formas de interação entre Governo e sociedade civil no mandato do ex-presidente Lula: mesas de diálogos e reuniões com os movimentos sociais, ouvidorias e precursora social que é um modelo de visita às regiões do país (Lambertucci, 2009).

Já no governo Dilma (2011-2014), foram realizadas 29 conferências. Há uma pequena diminuição na realização de conferências, sendo realizadas em média sete por ano, enquanto no governo Lula foi, aproximadamente, nove por ano. Na cultura, em 2014, ocorreu a $3^{\text {a }}$ Conferência Nacional de Cultura. Nota-se que a escuta pública e a participação nas políticas públicas vem sendo uma prática constante no governo petista. No entanto, nem sempre isso ocorreu tanto no campo da gestão pública, como mais especificamente no âmbito cultural.

\section{Políticas culturais nos anos 2000 no Brasil}

A partir de 2003, também se identifica uma mudança na gestão cultural. Esta se inicia desde o "olhar" para a cultura, ou seja, a ampliação do conceito de cultura e, consequentemente, a prática desse alargamento, que se reflete em políticas culturais mais inclusivas. Por conseguinte, o termo passou ser compreendido pelo viés ou dimensão antropológica, de maneira mais abrangente, e que foi amplamente utilizada e divulgada pelo Ministério da Cultura na gestão do ex-ministro Gilberto Gil (2003-2008) e nas seguintes administrações. Essa visão está em consonância com o projeto de governo de Lula (PT, 2002) e com a definição ampliada de cultura proposta pela Organização das Nações Unidas para Educação, Ciência e Cultura (Unesco), durante a conferência mundial em 1982, no México. A organização internacional considera

culture may now be said to be the whole complex of distinctive spiritual, material, intellectual and emotional features that characterize a society or social group. It includes not only the arts and letters, but also modes of life, the fundamental rights of the human being, value systems, traditions and beliefs; that it is culture that gives man the ability to reflect upon himself. It is culture that makes us specifically human, rational beings, endowed with a critical judgement and a sense of moral commitment. It is through culture that we discern values and make choices. It is through culture that man expresses himself, becomes aware of himself, recognizes his incompleteness, questions his own achievements, seeks untiringly for new meanings and creates works through which he transcends his limitations. (Unesco, 1990, p.41)

Além de difundir e influenciar os países membros com essa conceituação, a Unesco também contribuiu para o debate e desenvolvimento das políticas culturais. Outro marco para as políticas culturais foi a criação do primeiro ministério da Cultura, na França, por André Malraux, em 1959. (Rubim, 2009, p, 85). Já no contexto brasileiro, as políticas culturais podem ser vistas, como nomeou Rubim (2010), a partir de "três tristes tradições": as ausências, os autoritarismos, que conjugados geram as instabilidades. As primeiras são características de dois cenários: da falta de políticas públicas para área cultural em sua época mais antiga, no Brasil colônia até o início do período republicano, e também no período neoliberal, durante o governo Fernando Henrique Cardoso (FHC) de 1995 a 2002, época denominada por vários autores (Rubim, 2010, p. 11; Dagnino, 2004; Avritzer, 1995) como "Estado mínimo".

Por sua vez, os autoritarismos se referem aos períodos ditatoriais (era Vargas e regime militar), nos quais foram criadas algumas instituições culturais e instrumentos de políticas culturais. Durante a era Vargas (1930-1945), foram implementadas as primeiras políticas públicas para cultura. No entanto, entre o final do primeiro governo Vargas (1945) até o início da ditadura militar foram poucas as ações do Estado para a cultura.

Além dos autoritarismos e das ausências nas políticas públicas de cultura, elencam-se fatores que contribuíram e/ou produziram instabilidades, entre eles estão: a descontinuidade na administração pública, ocasionada pela troca de gestores; a fragilidade política na e da área; e a falta de reconhecimento, seja no âmbito público ou privado, da relevância da cultura para o desenvolvimento social do país. (Vilutis, 2012). 
Em 2003, há mudança na compreensão de cultura, que passa a ter uma vista por um viés antropológico, bem como se levando em consideração um modelo participativo de governança. A cultura é entendida também "como direito e um dos princípios basilares da cidadania". (Canedo, et al., 2010, p.30). Para além da mudança desta concepção, as políticas passam a ter os "fazedores" (artistas, mestres e mestras de saber popular) também como público participativo, bem como o Estado retoma o papel principal na execução das políticas, ao invés do mercado, que assumiu papel central no período neoliberal. Até mesmo áreas como culturas populares e indígenas, que não faziam parte do rol de políticas públicas, passam a ser inseridas. Nesse sentido, há também um aprimoramento das instituições e mecanismos democráticos e participativos, como Conselhos, Colegiado e outros, principalmente por terem novas formas de interação com a sociedade civil.

\section{Políticas para as culturas populares: um breve histórico}

Consideram-se as culturas populares brasileiras como um campo que compreende uma ampla diversidade de manifestações, saberes e práticas culturais, sendo suas origens iniciadas com a colonização europeia, que gerou processos culturais de hibridizações entre etnias portuguesas, indígenas e africanas, além de influências francesa, holandesa e outras. (Bezerra, 2014, p.36).

De acordo com Ayala e Ayala (2002, p.11), no período Republicano, ao final da segunda metade do século XIX, observa-se que o interesse pelos estudos do popular se alicerça na busca do "genuíno povo brasileiro". A partir do século XX, os estudos sobre o popular passam se pautar no interesse de descobrir uma identidade autêntica e própria, ou de uma "cultura brasileira". (Bezerra, 2014, p.38).

O movimento folclorista (1947-1979) tem papel fundamental na criação, desenvolvimento e articulação de políticas para as culturas populares, mesmo tendo sido em grande parte derrotado ao longo do processo de consolidação do campo intelectual brasileiro. (Vilhena, 1997, p.75). A política cultural tinha como foco a valorização e a formação da nacionalidade, ou uma identidade nacional. Assim, a cultura popular ou folclore foi utilizado para reforçar essa ideia. Aliás, é com esse viés que a cultura popular vai ser representada ao longo da história da política cultural no Brasil, até metade dos anos 1980, momento em que o país passou pela redemocratização e início de uma política voltada para lógica neoliberal. (Bezerra, 2014, p.42).

No período democrático, entre os governos ditatoriais, há uma ausência do Estado na direção e formulação de uma política para as culturas populares, com exceção de algumas ações relevantes para o segmento, entre as quais se destacam as intervenções do SPHAN, a Campanha de Defesa do Folclore (1958), primeiro órgão permanente dedicado à cultura popular, subordinada ao recém-criado MEC. (Vilhena, 1997; Rubim, 2007; Bezerra, 2014). Nessa época, também foi criada a Comissão Nacional de Folclore (CNFL), em 1947, no âmbito do Instituto Brasileiro de Educação, Ciência e Cultura (IBECC), órgão ligado ao Ministério das Relações Exteriores e com a recomendação da Unesco. Criada por Renato Almeida (1895-1981), a Comissão contribuiu para instituir comissões estaduais, bem como foram realizados vários congressos em âmbito nacional e estadual.

No início de 1960 - período marcado pela política desenvolvimentista -, ocorreu uma disputa em torno dos conceitos de folclore e culturas populares. Com o projeto e a ideologia desenvolvimentista, nesse momento a noção de folclore passa a ter um significado negativo. Por conta, disso inicia-se a formulação de uma distinção entre folclore e cultura popular, principalmente feita pelos Centros Populares de Cultura (CPC) da União Nacional dos Estudantes (UNE). O folclore passou a significar tradição, e cultura popular transformação (Ayala e Ayala, 2002; Bezerra, 2014). Com o golpe militar, em 1964, as mobilizações do movimento folclórico são enfraquecidas. A Campanha em Defesa do Folclore continuou até que em 1979, quando foi incorporada pela Funarte e passa a se chamar Instituto Nacional do Folclore. Já após o período ditatorial, em 1990, o órgão é denominado como Coordenação de Folclore e Cultura Popular; sendo atual- 
mente conhecido como Centro Nacional de Folclore e Cultura Popular, que é o único órgão federal a tratar das questões relativas à cultura popular no país.

Com a volta do regime democrático, nos anos 1990, praticamente inexiste política paras culturas populares, pois as visões dos governos Collor, Itamar e FHC são baseadas em uma lógica neoliberal, com destaque para o investimento privado na cultura. Assim, na história das políticas culturais, o segmento ocupou um lugar reduzido institucionalmente. (Vilhena, 1997).

As culturas populares passam a se constituir enquanto campo para desenvolvimento de política pública a partir de 2003, com ações importantes como os I e II Seminário Nacional de Culturas Populares e Tradicionais, que surgem de uma demanda popular (dos movimentos dos Fóruns de Culturas Populares de São Paulo e Rio de Janeiro) e a partir deles se inicia a discussão da criação de uma câmara ou colegiado setorial para área, vinculado ao então recém-reinstalado Conselho Nacional de Política Cultural (2005). Este órgão é parte integrante do Sistema Nacional de Cultura (SNC).

\section{Sistema Nacional de Cultura e Conselhos}

A Constituição Federal (1988) estabelece que o regime federalista, bem como está pautada na soberania popular. Nesse sentido, no governo Lula e nas gestões de Gilberto Gil e Juca Ferreira, à frente do Ministério da Cultura (MinC), buscou-se estabelecer políticas, programas e ações que reforçassem e colocassem em prática, pela primeira vez no Brasil, o pacto federalista no campo cultural. (Barbalho, Barros \& Calabre, 2013). Dentre as principais iniciativas, estão as Conferências Nacionais, o Plano Nacional e, principalmente, o Sistema Nacional de Cultura.

Como foi apontado, além de fazer valer os preceitos constitucionais, a concepção do SNC fez parte do projeto político de Lula (PT, 2002). De acordo com Reis (2008, p.55), lideranças políticas de apoio à candidatura do $\mathrm{PT}$, em 2002, antes mesmo de ganhar a eleição presidencial, atribuíram ao Ministério da Cultura o compromisso de implantar o SNC. A autora considera esse fato problemático no sentido de que as propostas do Programa resultaram de um grupo político, especialmente do PT, e não da frente do governo como um todo; sendo que a composição inicial do MinC não agregou, ou manteve, muitos dos principais envolvidos na elaboração do documento da campanha. (Reis, 2008, p.57).

Além disso, outro entrave apontado por Reis (2008), e também por Barbalho (2014), é que no início da implementação do Sistema as disputas internas entre membros do PT e aliados de Gil ou entre os próprios aliados do Ministro impactaram negativamente no desenvolvimento dessa política. (Reis, 2008, p.56; Barbalho 2014, p.193). Ademais desses problemas iniciais citados por Reis (2008) e Barbalho (2014), considera-se que a disputa interna, a troca de gestores e servidores na Secretaria de Articulação Institucional (SAI), órgão responsável pelo SNC, e sua equipe reduzida e mudanças de procedimentos do Programa também impactaram no avanço do Sistema, bem como de elementos que o instituem, a exemplo do Conselho e seus colegiados.

A cultura se inspira pelas áreas de saúde, assistência social e educação, sobretudo o primeiro segmento, pois o Sistema de Cultura possui várias similaridades com o Sistema Único de Saúde (SUS). Dentre as semelhanças entre os sistemas, estão o federalismo cooperativo, bem como a divisão de atribuições e responsabilidades entre os entes federativos; os princípios e as diretrizes dos Sistemas; o repasse de recursos e a criação de instâncias de controle social (Conselhos e Conferência). Lembra-se que, no entanto, no campo cultural o repasse de verbas para municípios e estados praticamente ainda não ocorre em sua plenitude. Teve-se apenas, em 2014, um edital de fortalecimento do Sistema Nacional de Cultura, por meio do qual o Ministério repassou recursos via Fundo Nacional de Cultura para seis Estados que completaram todo o processo de adesão ao Sistema. Os contemplados foram Acre, Bahia, Ceará, Paraíba, Rondônia e Rio Grande do Sul. O total de recursos desse primeiro de $\mathrm{R} \$ 30$ milhões.

Mesmo com prerrogativa constitucional, somente a partir dos anos 2000 que, do ponto de vista operacional e político, o federalismo na cultura realmente se inicia. A base conceitual desse 
modelo de gestão proposto pelo SNC é a tridimensionalidade da cultura; ou seja, é compreendida a partir de três dimensões simbólica, cidadã e econômica. Essa concepção está em coerência com a definição expressa na própria Constituição Federal, que em seu artigo 216-A, diz,

O Sistema Nacional de Cultura, organizado em regime de colaboração de forma descentralizada e participativa, institui um processo de gestão e promoção conjunta de políticas públicas de cultura, democráticas e permanentes, pactuadas entre os entes da Federação e a sociedade, tendo por objetivo promover o desenvolvimento humano, social e econômico com pleno exercício dos direitos culturais. (Brasil, 1988, com atualização em 30 nov. 2012).

O Sistema Nacional de Cultura é integrado pelos Sistemas Estaduais e Municipais de Cultura, com suas respectivas instâncias e elementos constitutivos; bem como é composto por nove elementos, dentre eles: órgão gestor de Cultura, MinC, que faz a coordenação do Sistema; instâncias de articulação, pactuação e deliberação, CNPC, CNC e Comissão Intergestores Tripartite (CIT); instrumento de gestão, Plano Nacional de Cultura; Sistema Nacional de Financiamento à Cultura; Sistema Nacional de Informações e Indicadores Culturais (SNIIC); Programa Nacional de Formação na Área da Cultura (PRONFAC); sistemas setoriais, Sistemas Nacional de Patrimônio Cultural, Sistema Brasileiro de Museus e Sistema Nacional de Bibliotecas Públicas. Desses componentes, apenas a CIT não foi implantada. Há também outros itens do SNC que precisam de reformulação de suas legislações ou ser melhor desenvolvidos.

\section{Conselhos de cultura}

Mesmo compondo o contemporâneo Sistema Nacional de Cultura (que se inicia a partir do governo Lula), segundo Lia Calabre (2010, p. 60), o modelo dos Conselhos de Cultura já existia desde a década de 1930. A autora ressalta que as políticas culturais, no Brasil, tiveram dois momentos de destaque: o Governo Vargas (1930-1945) e parte da ditadura militar (1966-1982). O Conselho Nacional de Cultura, por exemplo, foi instituído por meio do Decreto-Lei ${ }^{\circ} 526$ de $1^{\circ}$ de julho de 1938, como órgão de cooperação do Ministério da Educação e Saúde (MES), na gestão do ministro Gustavo Capanema.

Apesar de não se ter informações da existência efetiva desse primeiro Conselho Nacional de Cultura, a gestão do ministro Gustavo Capanema é tida como o período inicial da elaboração de uma permanente política cultural. No período militar, entre as décadas de 1960 e 1970, de acordo com Lia Calabre (2010, p.66), as questões de cultura ganharam uma maior importância dentro do setor público. Em fevereiro de 1961, foi promulgado o Decreto $n^{\circ} 50.293$, criando o Conselho Nacional de Cultura. Observa-se um apagamento da memória, pois em nenhum momento se faz referência ao primeiro conselho.

Em novembro de 1966, é criado o Conselho Federal de Cultura (CFC), por meio do DecretoLei $n^{\circ} 74$. Porém, o Conselho foi instalado apenas no ano seguinte. (Calabre, 2010). Já no fím do período ditatorial ocorrem mobilizações sociais pelas eleições diretas. Tem-se também a promulgação da Constituição de 1988, considerada a Constituição Cidadã por prever em seu texto direitos para as minorias excluídas do processo político-social e principalmente por inserir a participação dos cidadãos na política brasileira, por meio de ações como iniciativa popular, referendo e plebiscito, dentre outras ações que reforçam a cidadania. Assim o esforço da construção da democracia no Brasil ganhou ímpeto após o fim da ditadura militar, em 1985.

Os conselhos são retomados principalmente a partir dos anos 2000 e com uma nova proposta, pois na contemporaneidade se busca a participação paritária, o controle social, com olhar para uma governança colaborativa. Dessa maneira, os atuais conselhos - que se iniciam a partir da Constituição Federal de 1988, mas na cultura se deu essencialmente a partir dos anos 2000 - não são apenas órgãos colegiados de assessoramento do governo e tampouco apenas são compostos por "notáveis", membros indicados pelo próprio governo. 
Conselhos de Política Cultural são instrumentos de participação e pactuação entre governo e sociedade civil, bem como são elementos fundamentais para a implantação dos sistemas municipais, estaduais e Nacional de Cultura, no Brasil. Esses sistemas de cultura visam a cooperação entre os entes federativos, a descentralização das políticas culturais, a participação da esfera civil, a instituição de uma política pública para cultura que ultrapasse governos, ou seja, criar política de Estado para Cultura.

\section{Participação e representação nos conselhos}

Para além de compreender o histórico dos conselhos e sua formação na sociedade brasileira, também é necessário conceituá-los. Nesse sentido, Pitkin (1967), citada por Lavalle, Houtzager e Castello (2006), considera que participação é autorrepresentação, isto é, nos conselhos a participação se faz a partir da representação, mas não apenas a do tipo "autorrepresentação"; há também a representação autorizada. Este formato ocorrer por duas formas: representação coletiva ou individual. (Lüchmann, 2008). Na primeira, os representantes vêm de entidades coletivas de segmentos ou setores; na segunda, os próprios cidadãos representam seus pares, sem necessariamente integrarem algum movimento social ou entidade.

Para que sejam autorizados esses representantes, há alguns meios, que variam de acordo com as regras de cada conselho. A representação autorizada pode ocorrer por eleição em fóruns, conferências, assembleias; dessa maneira seguem o modelo da democracia representativa. Mas esses representantes também podem ser indicados; ou até mesmo existir formas de autorização combinadas, nas quais há assentos já pré-definidos, mais também há escolha por indicação e/ou eleição. (Lüchmann, 2008). Dessa maneira, com relação à representação nos Conselhos é importante se analisar a representatividade, tendo em vista a pretensão de legitimidade dos cidadãos nestes espaços. Nesse aspecto, Borba e Lüchmann apontam que a legitimidade desta representação política está intimamente relacionada a dois elementos, quais sejam, a atuação e configuração da sociedade civil, e o desenho institucional, ou seja, o conjunto de regras, critérios, espaços, normas, leis, que visam a fazer valer e promover a representatividade dos conselheiros. (Borba e Lüchmann, 2010, p.232). No caso do Colegiado, a representação é do tipo individual e o mecanismo para escolha é eleição em fóruns e/ou conferências.

\section{Conselho Nacional de Política Cultural (CNPC)}

Partindo da concepção de participação apontada por Lüchmann (2008) e Borba e Lüchmann (2010), analisamos o Conselho Nacional de Política Cultural, em sua ação para e nas culturas populares. Nesse sentido, ressaltamos que o Conselho compõe o Sistema Nacional de Cultura, bem como é um de seus elementos constitutivos obrigatórios (artigo $2^{\circ}$ do Decreto 5520/2005, com alterações do Decreto $n^{\circ} .6973 / 2009$ ). Sua previsão legal é a Lei ${ }^{\circ}$. 9649, de 1998, criada durante a gestão do presidente Fernando Henrique Cardoso, mas suas atribuições estão no Decreto $\mathrm{n}^{\circ} .5 .520$ (2005) e no Decreto $\mathrm{n}^{\circ} .6 .973$ (2009), norma esta que é a seguida pelo órgão e define com uma de suas finalidades: a participação social; como pode ser visto no artigo $1^{\circ}$, II: "contribuir para a implementação de políticas culturais democráticas e permanentes, pactuadas entre os entes da federação e sociedade civil." (Brasil, 2005, grifo nosso).

O Conselho foi empossado em 2007 e integra uma política do governo Lula que visou à descentralização, à gestão participativa e à institucionalização do campo cultural. Com base na classificação de Cunha Filho. (2010, pp.92-101). Criado pelo poder Executivo, vinculado à Secretaria de Articulação Institucional do Ministério da Cultura, o CNPC possui natureza política de hierarquia infralegal, sem referência constitucional. 


\section{Colegiado Setorial de Culturas Populares: resultados e apontamentos}

Já em 2005, quando se decreta a norma que reinstitui o CNPC, iniciam-se as Câmaras Setoriais para segmentos das artes ligadas à Fundação Nacional das Artes (FUNARTE), depois em algumas áreas - como Culturas Populares e Culturas Indígenas - instalaram-se Grupos de Trabalho e, por fim, instituíram-se os Colegiados Setoriais.

No caso das Culturas Populares, em 2007, quando (tardiamente) começam as reuniões do CNPC, a área ganha um assento, mas não conta com Colegiado. Desde 2005, período em que se realizou o primeiro seminário nacional do setor, os coletivos e fóruns culturais compostos por atores da sociedade civil reivindicavam uma instância participativa em nível nacional. Com o GT criado para organização dos seminários de culturas populares, em 2005 e 2006, começa-se a construção do colegiado. Em 2009, o MinC estabelece as diretrizes para a seleção de delegados para comporem uma pré-conferência de culturas populares, evento no qual foram eleitos os membros do Colegiado para 2010-2012.

Para compor esse órgão, os interessados se inscreveram no site do MinC e a partir da seleção escolheram-se delegados para representar os Estados e/ou regiões nas Pré Conferências Setoriais de Cultura (2010). Somente depois que foram eleitos os representantes que compuseram o Colegiado de Culturas Populares. Sendo assim, foram escolhidos 15 representantes titulares e 15 suplementes.

A eleição dos membros para o Colegiado foi feita pelos próprios representantes da sociedade civil, com acompanhamento de membros da Comissão Eleitoral da CNC. A composição do órgão está de acordo com o seu Regimento, o qual diz que o Plenário deve possuir cinco representantes do poder público e 15 representantes da sociedade civil, sendo que deve contemplar as cinco macrorregiões administrativas e os diversos segmentos que compõem o setor das Culturas Populares: mestres, fazedores de cultura, pesquisadores e mediadores. Ou seja, a regra considera a ideia de representatividade a partir de uma lógica territorial e descentralizada.

Ainda sobre a composição do Colegiado, o RI diz que dentre os representantes do poder público, é membro nato o representante da entidade finalística integrante do sistema MinC cujas atribuições correspondam ao campo setorial do Colegiado.

Para compreender o perfil dos membros da sociedade civil eleitos em 2010, estabeleceramse os seguintes critérios: 1) sexo; 2) representatividade regional; 3) atuação na cultura; 4) atuação em órgãos conselhistas ou entidade do terceiro setor. A verificação desses dados toma por base a composição publicada na Portaria $n^{0} .84$, de 23 de julho de 2010.

No que compete ao primeiro ponto, $70 \%$ dos representantes são homens e apenas $30 \%$ mulheres, ou seja, não há um equilíbrio da representação no quesito gênero. No que concerne ao segundo aspecto, as cinco regiões têm representantes nas três linhas e, ao todo, 21 estados estão representados. Além disso, as regiões Sul e Sudeste têm uma representatividade $100 \%$ dos estados. Já o Centro-oeste é de $75 \%$, a Norte é de $71 \%$ e Nordeste, $66 \%$. Ou seja, todas as regiões possuem mais de $50 \%$ das unidades da federação com assentos no Colegiado. Há um equiparidade nesse quesito, assim como atende as normas do CNPC e do próprio Colegiado. Sobre os critérios três e quatro, o perfil é diversificado, mas os membros estão diretamente ou indiretamente ligados às culturas populares, seja pela trajetória pessoal e profissional, com atuações nas áreas de produção, pesquisa ou, até mesmo, gestão.

Para o biênio seguinte (2012), ocorrem mudanças no processo de eleição de delegados para evento nacional, no qual foram eleitos os membros do Colegiado. A principal delas é que o debate e a escolha dos delegados se dão apenas pela internet; assim, acarretaram em uma menor representatividade. Com relação a isso, no período aberto para inscrição nos fóruns virtuais, muitas foram as reclamações da sociedade civil no que diz respeito ao acesso ao hotsite das setoriais. Além disso, acrescenta-se que: 1) a linguagem da norma que rege o processo, em alguns trechos, é complexa. Outro ponto, que persiste mesmo com as críticas ao processo anterior, é no cadastramento pela Internet e a quantidade de documentos que comprovem a atuação na cultura. 
Desse modo, as unidades federativas que ultrapassassem o número máximo de delegados para nacional (6) tiveram o excedente redistribuído entre outros estados que não tiverem alcançado o número de vagas. Esse mecanismo gerou uma concentração de estados na composição do Colegiado de Culturas Populares. Enquanto em 2010 o Colegiado teve uma composição de 20 estados cm representantes eleitos, entre titulares e suplentes; em 2012, o quantitativo passou para 14 estados. Ocorreu uma concentração nas seguintes unidades da federação: Pará, São Paulo, Alagoas, Ceará.

No segundo mandato do órgão destaca-se que uma vaga de suplente da categoria "mestres de cultura popular" não foi preenchida, pois havia mais representantes presentes no evento que se aplicavam a essa categoria; o que demonstra já um reflexo negativo do formato escolhido para eleger representantes. Assim, consideram-se apenas 29 assentos, para efeitos da análise dos dados a seguir. No que diz respeito ao sexo: $55 \%$ dos representantes são homens e $44 \%$ mulheres, ou seja, há um maior equilíbrio da representação no quesito gênero se compararmos com a composição anterior. No que concerne à representatividade regional, as cinco regiões têm representantes nas três linhas e, ao todo, 14 estados estão representados, ou seja, uma queda de representatividade de seis estados com relação ao biênio anterior.

Nenhuma região obteve uma representatividade $100 \%$ dos estados. Na verdade, assim como no processo eleitoral ocorreu maior concentração das unidades da federação, na composição também isso se fez presente. Na região Norte, apenas três estados garantiram assentos (42\%), além disso, quatro conselheiros são do Pará. No Nordeste, quatro estados têm representantes (44\%). No Centro-oeste, há representantes do Distrito Federal e Goiás (50\%). No Sudeste, apenas Minas Gerais não obteve assento no Colegiado, totalizando $75 \%$ de representatividade dos estados. No Sul, somente Paraná não contou com vaga no órgão, assim a representatividade dos estados foi de $75 \%$. Há um equiparidade regional nesse quesito, assim como atende as normas do CNPC e do próprio Colegiado, no que diz respeito a todas as regiões terem representantes no Colegiado. Mas não poda-se deixar de pontuar que ocorreu uma concentração, principalmente, dos estados do Pará e Alagoas.

Cabe ainda ressaltar, que 16 conselheiros são membros da Rede de Culturas Populares e Tradicionais, mas a maioria participa da lista de discussão, mesmo não sendo membro. Ou seja, mais da metade dos representantes atuavam anteriormente em redes ou coletivos da área. Esta composição apresenta algumas diferenças com relação a anterior: há previsão de representação por regiões, mas as outras categorias não são subdivididas entre as cinco regiões. Além desses dados, nota-se que nas duas composições ocorre a representação do tipo individual; ou seja, os membros do colegiado não representam instituições ou entidades, apesar de alguns as integrarem, eles estão representando suas regiões, de acordo com suas categorias (mestres, pesquisadores, etc.).

Durante o primeiro ano (2010) se deu a maior parte das ações de participação no Colegiado. Naquele período, ainda não havia ocorrido troca de gestão no MinC e nem no governo federal. As principais ações desenvolvidas foram a construção do Plano Nacional de Cultura, sendo cada colegiado setorial responsável por elaborar metas e ações relacionadas ao seu segmento; criação de regimento interno do Colegiado de Culturas Populares e do Plano Setorial de Culturas Populares.

A partir do segundo ano de trabalho do Colegiado Setorial de Culturas Populares observa-se que com a mudança ministerial o órgão, bem como a continuidade de suas ações, sofreu uma estagnação. Assim, acredita-se que o intuito de se construir políticas de Estado - um dos principais pontos enfatizados pelo governo Lula - não conseguiu ser alcançado.

\section{Principais resultados}

De 2011 a 2014, foi realizada a pesquisa sobre o órgão, que teve como métodos: análise de atas das reuniões ocorridas entre 2010 a 2014, entrevistas semiestruturadas com cinco conselheiros do Colegiado, bem como foi aplicado um questionário estruturado, por meio de plataforma virtual, obtendo-se um total de 70 respostas. 
Quanto ao questionário, dentre os participantes, 54\% são homens e 46\% mulheres, o que demonstra certo equilíbrio no que diz respeito à questão de gênero, pois a diferença é menor que $10 \%$. No que se refere à escolaridade, $43 \%$ possuem pós-graduação concluída e em andamento; $36 \%$ são graduados e graduandos; $6 \%$ não concluíram o ensino superior; $11 \%$ têm ensino médio completo e $4 \%$ não o finalizaram. Nesse sentido, identifica-se um perfil altamente escolarizado de conselheiros em comparação à população brasileira, a qual possui uma escolaridade média de 7,1 anos de estudo, o que equivale ao ensino fundamental incompleto (IBGE, 2010).

Identificou-se que apenas $23 \%$ dos 70 entrevistados declararam ter acesso às informações sobre o órgão. Ou seja, um total de 54 pessoas (77\%) não sabe sobre a atuação do órgão. Isto demonstra tanto o problema da representatividade quanto do déficit da utilização dos canais de comunicação. Nesse sentido, de acordo com os entrevistados, os 16 que têm informações usam como meios de comunicação ou as fontes das informações, principalmente, a Rede de Culturas Populares e Tradicionais (RPCT) (3) e amigos que são participantes do Colegiado (3). Outras maneiras são: site do MinC (2), redes sociais (2), notícias, Universidade, outras redes ou egrupos (Rede Brasileira de Teatro de Rua), site do CNPC.

Ainda no que diz respeito a fragilidade na representatividade, questionou-se se os participantes da pesquisa conheciam seus representantes regionais. A maioria $(71 \%)$ informou não saber quem são os conselheiros e/ou não interagir com eles. No que se refere a qualidade das divulgações, fez-se a seguinte pergunta: "Como avalia a divulgação das ações do Colegiado?". A maioria (27\%) julga ser péssima a divulgação. Apenas uma pessoa (1\%), avaliou como ótima.

Um dos principais resultados da atuação do Colegiado foi a elaboração do Plano Setorial de Culturas Populares, que é um anexo do Plano Nacional de Cultura. O primeiro documento foi aprovado em Plenário do Colegiado em novembro de 2010. Já teve uma edição atualizada em 2012, mas a maioria dos atores entrevistados alega não ter conhecimento do instrumento.

Além das questões no tocante à representatividade, algumas críticas feitas pelos próprios conselheiros foram: 1) construção das pauta não é feita de modo coletivo, respeitando a governança colaborativa; 2) desconsiderar reivindicações feitas pelo Pleno como, por exemplo, o processo eleitoral de 2012 e a não divulgação do Plano Setorial de Culturas Populares; sendo que estes dois últimos pontos contribuem para o déficit de comunicação com as bases e para os entraves quanto à representatividade.

\section{Apontamentos finais}

O Colegiado Setorial de Culturas Populares pode ser considerado com uma experiência de valorização das culturas populares e, também, um marco para as políticas públicas do segmento, por instituir um canal de participação entre atores sociais de uma área tão fragmentada e com histórico de baixa visibilidade e relevância nas gestões anteriores do Ministério da Cultura.

Fragmentada, pois as culturas populares agregam uma diversidade de atores sociais de diferentes manifestações e saberes populares, assim como outros sujeitos que compõem as várias dimensões da cadeia produtiva do setor; mas que não há uma organização e uma articulação consolida no país. Ou seja, ainda não há uma conformação do campo; mesmo com as várias tentativas de institucionalizar e consolidar as culturas populares enquanto saber acadêmico, sendo estas ocorridas a partir da década de 1940 e encabeçadas pelo movimento folclórico. Ou seja, ainda há várias limitações e obstáculos a serem superados. Mas é de se destacar que a partir de 2003, várias ações do Ministério da Cultura buscam ultrapassar esses limites. Dentre elas, os seminários de culturas populares foram de extrema importância para que se inicie não somente o próprio Colegiado, mas também uma concepção de política pública setorial. O próprio Colegiado é uma maneira de superar as limitações e as fragilidades que a área, tradicionalmente, sempre teve.

Identificou-se que essa instância ainda tem que avançar, bem como se reconhece que, por vezes, a atuação política dos conselheiros pode ser vista como bastante instrumental, ou seja, competências restritas e ligadas (muitas vezes) aos interesses mais próximos e imediatos da or- 
ganização a que se vincula. Dessa maneira, exemplos práticos foram vistos que corroboram essa "atuação mais instrumental", quando alguns membros do Colegiado questionam a elaboração das pautas e reivindicam uma construção coletiva.

Vê-se um aprimoramento na prática participativa de um biênio para o outro. No entanto, fragilidades e restrições anteriores ainda são presentes. Por conseguinte, faz-se imprescindível também suprir a lacuna quanto às normas. Afinal, atualmente o Conselho Nacional de Política Cultural está ancorado em uma norma de hierarquia infralegal, um decreto presidencial, que pode ser alterado ou revogado a qualquer momento ao critério do chefe do Executivo. Assim como é preciso que se reveja o regimento do próprio colegiado, no tocante a considerar aspectos importantes da atuação dos conselheiros, tais como competências mais deliberativas, para que se fuja do perigo de um órgão com caráter mais instrumental.

Analisou-se que a representatividade desses conselheiros é limitada, pois há fatores que interferem na efetividade representativa, como mobilização da sociedade civil, acesso às informações públicas do setor, dentre outros. Ademais, nota-se, a partir da amostra coletada nesta pesquisa que a maioria dos atores das culturas populares não conhece o Colegiado e suas ações. Um dos problemas que acarreta isso é, novamente, a representatividade e também a subutilização de importantes canais de comunicação, a exemplo do site do CNPC ou o blog do Colegiado, que é desatualizado.

A abrangência não alcança a enorme diversidade de "fazedores" e de outros atores da área, seja demonstrado pelo não conhecido do Colegiado e/ou por não saber quem são seus representantes - o que demonstra também fragilidade na representatividade - ou por não ter informações sobre ações e atividades. Exemplo prático é o Plano Setorial de Culturas Populares, instrumento dos mais importantes e que apresenta institucionalidade ao ser anexado ao Plano Nacional de Cultura, mas que não é conhecido pela maioria dos 70 entrevistados da pesquisa. Conclui-se que, mesmo diante da relevância do órgão, sua efetividade é comprometida por fatores externos e internos à sua atuação, quais sejam: descontinuidades; problemas de ordem de gestão (equipe, organização, estrutura interna da instância); disputas pessoais, internas e partidárias; representatividade; subutilização de canais de comunicação. Resultando, assim, em um desconhecimento da maioria dos entrevistados participantes da pesquisa.

Fazem-se necessários dois movimentos, um de maior institucionalidade e aprimoramento dos mecanismos de transparência pública do Conselho e do Colegiado; e outro de maior mobilização do segmento das culturas populares e maior articulação entre representantes e representados.

\section{Agradecimentos}

Agradeço ao Programa de Pós Graduação Multidisciplinar Cultura e Sociedade (Pós Cultura), da Universidade Federal da Bahia (UFBA) e a Fundação de Amparo à Pesquisa do Estado da Bahia (FAPESB). 


\section{REFERÊNCIAS}

Avritzer, L. (1995). Transition to Democracy and Political Culture: an Analysis of the Conflict between Civil and Political Society in Post-Authoritarian Brazil. Constellations I 2(2), 242-267.

Ayala, M. e Ayala, M. I. (2002). Cultura Popular no Brasil. São Paulo, Brasil: Editora Ática.

Barbalho, A.; Barros, J. M. e Calabre, L. (Org.). (2013). Federalismo e políticas culturais no Brasil. (pp. 115-130). Salvador, Brasil: EDUFBA.

Bezerra, J. (2014). Quando o popular encontra a política cultural: a discursividade da cultura popular nos Pontos de Cultura "Fortaleza dos Maracatus", "Cortejos Culturais do Ancuri" $e$ "Boi Ceará”. 178 f. Dissertação (Mestrado Acadêmico em Políticas Públicas e Sociedade). Fortaleza, Brasil: Universidade Estadual do Ceará.

Borba, J.e Lüchmann, L. H. H. (2010). A representação política nos Conselhos Gestores de Políticas Públicas. Urbe: Revista Brasileira de Gestão Urbana, 2(2), 229-246.

Brasil. Casa Civil. (1998). Constituição Federal. Brasília, DF, Brasil.

Brasil. Decreto $n^{0}$ 5.520. (2005). Institui o Sistema Federal de Cultura. Brasília, DF, Brasil.

Brasil. Ministério da Cultura. (2010). Portaria $n^{\circ} 28$. Publica Regimento Interno do Conselho Nacional de Política Cultural. Brasília, DF, Brasil.

Calabre, L. (2010). Politicas Culturais no Brasil: história e contemporaneidade. Fortaleza, Brasil: Banco do Nordeste do Brasil.

Canedo, et al. (2010). Políticas públicas de cultura: os mecanismos de participação social. In: Rubim, Antônio Albino Canelas (Org.) Políticas culturais no governo Lula. Salvador, Brasil: EDUFBA.

Cunha Filho, F. H. (2010). Conselhos no Vigente Modelo Constitucional do Brasil: paradigma para a construção dos congêneres culturais. In: Rubim, Iuri; Fernandes, Taiane e Rubim, Antonio Albino Canelas (Org.). Politicas Culturais, Democracia \& Conselhos. Salvador, Brasil: EDUFBA.

Dagnino, E. (2002). Sociedade civil, espaços públicos e a construção democrática no Brasil: limites e possibilidades. In: Dagnino, E (Org.). Sociedade civil e espaço público no Brasil. São Paulo, Brasil: Paz e Terra.

- (2004). ¿Sociedade civil, participação e cidadania: de que estamos falando? In: Daniel Mato (Coord.), Politicas de ciudadanía y sociedad civil en tiempos de globalización. (pp.95110). Caracas, Venezuela: FACES, Universidad Central de Venezuela.

IBGE. Instituto Brasileiro de Geografia e Estatística. (2010). Pesquisa de Informações Básicas Municipais: perfil dos municípios brasileiros 2009. Rio de Janeiro, Brasil.

Lambertucci. A. R. (2009). A participação social no Governo Lula. In: Avritzer. L. (Org). Experiências nacionais de participação social. (Coleção Pensando a Democracia Participativa). São Paulo, Brasil: Cortez.

Lavalle, A. G., Houtzager, P. P. e Castello, G. (2006). Democracia, pluralização da representação e sociedade civil. Lua Nova. (67), 49-103. ISSN 0102-6445. http://dx.doi.org/10.1590/S0102-64452006000200004.

Lüchmann, L. H. H. (2008). Participação e representação nos conselhos gestores e no orçamento participativo. Caderno CRH, UFBA. 21(52). 87-97.

Organização das Nações Unidas para a Educação, a Ciência e a Cultura (UNESCO). (1990). Records of the General Conference. Paris, Francia: UNESCO. Disponível em:

http://unesdoc.unesco.org/images/0008/000846/084696e.pdffpage=242. Acesso em 23 maio 2014.

Pateman, C. (1992). Participação e teoria democrática. Rio de Janeiro, Brasil: Paz e Terra.

Pereira, M. A. G. (2007). Modelos democráticos deliberativos e participativos: similitudes, diferenças e desafios. In: Dagnino, Evelina e Tatagiba, Luciana. Democracia, sociedade civil e participação. Chapecó, Brasil: Argos. 
Pesquisa sobre colegiado setorial de culturas populares. Salvador, BA, 2011. Disponível em: https://docs.google.com/forms/d/1yoeqYhTrmbJsXebdfnTB4c1-

3xEAYXFfhzaufFF5cTY/viewform. Acesso em: 28 dez. 2014.

Pitkin, H. (1997). The concept of representation. Berkeley, USA: University of California Press.

Partido dos Trabalhadores (PT). (2002). A Imaginação a serviço do Brasil. São Paulo, Brasil: PT.

Pólis, INESC. (2011). Arquitetura da Participação no Brasil. Relatório de Pesquisa. Disponível em http://www.polis.org.br/uploads/1262/1262.pdf.

Regimento Interno do Colegiado Setorial de Culturas Populares, a ser encaminhado ao Plenário do CNPC e submetido à aprovação do Ministro de Estado da Cultura. [S.1.: s.n.], [2010]. Disponível em:

http://www.cultura.gov.br/documents/10907/0/Regimento+Interno+Culturas+Populares/5f 806987-5358-4a61-b94e-95bab0e57aad?version=1.0. Acesso em: 20 jan. 2015.

Reis, P. F. (2008). Políticas Culturais do Governo Lula: análise do sistema e do plano nacional de cultura. Salvador, Brasil: Universidade Federal da Bahia.

Rubim, A. A. C. (Org.). (2010). Politicas culturais, democracia e conselhos de cultura. Salvador, Brasil: EDUFBA.

- (2009). Políticas Culturais e novos desafios. Revista Matrizes (USP). 2(2), 92-115.

- (2007). Políticas Culturais: entre o possível e o impossível. In: Nussbaumer, Gisele Marchiori (Org.). Teorias e Políticas da Cultura. Salvador, Brasil, EDUFBA.

- (2010). Políticas Culturais no Governo Lula. In: Rubim, Antonio Albino Canelas (Org.). Politicas culturais no governo Lula. Salvador, Brasil: EDUFBA.

Santos, B. S. de. (2002). Democratizar a democracia: os caminhos da democracia participativa. Rio de Janeiro, Brasil: Civilização Brasileira.

Vilhena, L. R. (1997). Projeto e Missão. O Movimento Folclórico Brasileiro, 1947-1964. Rio de Janeiro, Brasil: Funarte/Fundação Getúlio Vargas.

Vilutis, L. (2012). Planos Municipais de Cultura e participação social no fortalecimento de políticas culturais. Salvador: Políticas Culturais em Revista. 5(2). 135-150.

\section{SOBRE A AUTORA}

Giordanna Santos: Doutora pelo Programa Multidisciplinar Cultura e Sociedade da Universidade Federal da Bahia (UFBA), linha de pesquisa Cultura e Desenvolvimento. Mestre em Estudos de Cultura Contemporânea (ECCO), na linha de pesquisa de Poéticas Contemporâneas, pela Universidade Federal do Estado de Mato Grosso (UFMT). Formada em Comunicação Social, Jornalismo, pela UFMT. Participou do Colegiado Setorial de Culturas Populares do Conselho Nacional de Política Cultural (CNPC), vinculado ao Ministério da Cultura (MinC). 